https://helda.helsinki.fi

\title{
Expertise as a domain in interaction
}

\section{Arminen, Ilkka}

2021-10-01

Arminen , I \& Simonen , M 2021 , ' Expertise as a domain in interaction ' , Discourse Studies , vol. 23 , no. 5 , 14614456211016797 , pp. 577-596 . https://doi.org/10.1177/14614456211016797

http://hdl.handle.net/10138/336288

https://doi.org/10.1177/14614456211016797

acceptedVersion

Downloaded from Helda, University of Helsinki institutional repository.

This is an electronic reprint of the original article.

This reprint may differ from the original in pagination and typographic detail.

Please cite the original version. 


\section{Expertise as a domain in interaction}

Ilkka Arminen \& Mika Simonen

University of Helsinki, Finland

contact: ilkka.arminen@helsinki.fi

Words: 9226

To be published in Discourse Studies 23; 2021/5. 


\section{Expertise as a domain in interaction}

\section{Abstract}

We start this article from Gilbert Ryle's (2009 [1949]) distinction between propositional knowledge, "knowing-that," and procedural knowledge, "knowing-how," and investigate how participants in interaction display orientation to the latter in various settings. As the knowledge of how things are done, know-how can be analyzed in terms of its relevance and consequentiality for parties in interaction. Similarly, as participants adjust their actions and understandings according to their sense of what they know and assume others to know, their know-how and its distribution may form the basis for adjusting and reshaping their actions, forms of participation and identities. In this sense, we aim at opening an investigation of know-how, and its conventionalized form, expertise, in interaction. In as much as it forms a distinct domain, a new research object-expertise in interaction-is formulated. Methodological issues of how to study expertise in interaction are discussed. The data are in English and Finnish.

\section{Keywords}

Deontics, EM/CA, epistemics, expertise, know-how, knowledge, morals, Gilbert Ryle 


\section{Introduction}

In recent years, epistemics has grown into a focal but also disputed topic in conversation analysis (CA) (Heritage 2012; 2013; Lynch \& Macbeth 2016; Lindwall et al. 2016; Drew 2018). The area concerns parties' adjustments of their actions and understandings according to their sense of what they know and assume others to know. The domain of epistemics is vast and many-sided, and it has attracted a significant amount of research and led to fine-grained conceptual distinctions about epistemic access, epistemic primacy and epistemic authority, as well as epistemic rights and responsibilities (Hayano 2013; Stivers, Mondada and Steensig 2011). The issues addressed also include the sources and basis of knowledge (see Pomerantz 1984). The discussion on "social sources of epistemic authority" (Raymond and Heritage 2006: 702) entails the role of expertise and experience (Heritage 2013). Yet, this interest has not resulted in thorough discussion of qualities of knowing, such as that between propositional and procedural knowledge in interaction.

In this article, we seek to explore that direction and analyze the way in which different qualities of knowledge are relevant for parties in interaction and consequential for their actions. In that way, we aim at opening for scrutiny a new research object - expertise in interaction - as a distinct domain. While it is not news that parties may orient to their expertise in interaction, and there have been numerous studies on professional practices that also discuss such expertise at work (e.g., Heath 2012; Maynard 2003; Mondada 2003), a systematic treatment of expertise and its role within the domain of knowledge in interaction has remained a distant goal.

To introduce the idea of expertise in interaction, we start with the philosopher Gilbert Ryle (1945; 2009 [1949]), who highlights the relevance of procedural knowledge, which as a "dispositional excellence" forms the basis for expertise. In everyday life, we "know" that it is a different thing "to know something" and "to know how something is done." Gilbert Ryle coined this in his famous distinction between "knowing-that" and "knowing-how": "When a person is described by one or other of the intelligence-epithets such as 'shrewd' or 'silly,' 'prudent' or 'imprudent,' the description imputes to him not the knowledge, or ignorance, of this or that truth, but the ability, or inability, to do certain sorts of things." (2009 [1949]), 16-17). Initially Ryle seemed to have tried to formulate different meanings of "knowing" through the uses of "to know" in ordinary language, but the uses of "to know" appear to vary (Brown 1970). Later Ryle's distinction has been defended in terms of the referents of the knowledge; knowing how concerning actions and knowing something propositions (Fantl 2008). Anyway, we still do not know, if it is relevant and consequential for parties in interaction.

Ryle himself is adamant that procedural knowledge cannot be reduced to propositional knowledge:

...when we describe some particular action as clever, witty or wise, we are imputing to the agent the appropriate dispositional excellence. The way in which rules, standards, techniques, criteria, etc., govern his particular performances is one with the way in which his dispositional excellences are actualized in those performances. It is second nature to 
him to behave thus and the rules, etc., are the living nerves of that second nature. To be acute and consistent in reasoning is certainly to apply rules of inference to the propositions considered. But the reasoner does not have both to consider propositions and to cast sidelong glances at a formula; he just considers the propositions efficiently. The rules are the rails of his thinking, not extra termini of it." (Ryle 1945, 14)

How "dispositional excellence"-and its conventionalized form, "expertise"-is taken into consideration in interaction can be formulated into a new research object. Following Ryle, we can operationalize a research question concerning a propositional knowledge/expertise distinction, suggesting that knowing-that and knowing-how may have different, even contradictory, implications for parties in interaction. In different settings, we get a sense of what the distinction may mean in practice. For instance, in pedagogic environments there are specified forms of pedagogies applied for teaching expert skills, which do not concern knowing something but knowing how to act. Rehearsing and apprenticeship may be the most common pedagogical formats for transferring expertise (Lave \& Wenger 1991). Expert skills and practices vary widely; they among others involve how to "see," or how to configure the body posture (Goodwin 1994; Hindmarsh 2010; Koskela \& Arminen 2012), how to learn to recognize clients' implicit requests, or how to defend authority (Nguyen 2012) ${ }^{\mathrm{i}}$. In all, expertise involves development and transformation of skills to meet the specific requirements of a particular, conventionalized practice. The studies of expertise in interaction concern relevance and consequentiality of knowledge and, in particular, conventionalized know how for interactants in conducting their talk and action in rule-based practices of interaction. For example, conducting standardized interviews requires expertise with the help of which the interviewer may tailor her/his performance to alternate between the requirements of standardization and maintenance of intersubjective understanding. In that way, the interviewer does not just rely on a mundane recipientdesign in delivering questions and response options, but also tries to maintain a procedural uniformity aimed at standardized quality within the limits of reciprocal understanding (Maynard et al. 2002; Whalen \& Vinkhuyzen 2000).

Expertise in interaction poses characteristic issues and challenges for its study, not least, as the meaning of expertise is fluid and contestable. On occasion, it is referred to as being owned by the experts; it may also be institutionally accredited entitlement, an activity-specific mastery of a task, or practical knowledge that is learned by experience. Further, expertise may be taken for granted and acquiesced to, or it may be topicalized and challenged, which makes it prone to be subjected on the old methodological debate on topic/resource (Lindwall et al. 2016). Expertise, the conventionalized forms of know-how, in interaction can be seen as a topic that draws together phenomena that have already been looked at in studies of institutional encounters. To open expertise for studies in interaction, we have to analyze both how participants come to identify expertise in their interaction and how we as analysts arrive at seeing expertise that may not be topicalized but a taken-for-granted aspect of interaction. Furthermore, we have to explore the procedural consequentiality of expertise in interaction, what is accomplished with expertise and how parties have oriented to excellence in interaction. We have to inspect the situated achievement of the display of expertise, as well as its reception: the expertise becoming acquiesced to and acknowledged, or contestable and contested.

In this article, we will discuss three themes concerning expertise in interaction. Utilizing the 
conceptual systematics of epistemics, we will first discuss how parties in interaction orient to expert status, which is related to but cannot be reduced to knowledgeability. Second, following the lead of expertise as the conventionalized dispositional excellence, we will explore its relationship with social practices and questions concerning the implications of facts that have a moral dimension and a link to the deontic authority. Third, we will address methodological issues of how to study expertise in interaction and what requirements the study of expertise sets for researchers. Finally, we conclude the article by a brief discussion on the moral embeddedness of expertise.

\section{Data and Methods}

We analyze a selection of cases from multiple contexts (e.g., from air traffic control training, courtrooms, health visitor's home visits, peer group therapy sessions, jobseekers' interviews, elderly care) spoken in American English, British English, or Finnish. For the analysis, we use ethnomethodological conversation analysis (Ten Have \& Psathas 1995; Sidnell \& Stivers 2013) in order to address expertise in comparison to propositional knowledge and to determine and detail the specificity of expertise in interaction. Founded on Ryle's distinctions regarding the types of knowledge, we explore how procedural knowledge surfaces in interaction. We aim to show how it manifests through specific practices and expert ways of doing things, thereby contributing an EM/CA angle to the study of expertise in interaction. We study cases where participants orient to expertise in interaction, and we analyze how they differentiate, relate and evaluate lay observations from expert visions. We also address the potentially adversarial relationship between lay observations and professional visions.

\section{Lay/expert distinctions and the realm of expertise}

Similarly to epistemic status (Heritage 2013), we can refer to expert status. Relative expertise access to a domain stratifies the participants, forming an expertise gradient between them, involving parties' joint understanding of their relative expertise in the field, expert status and the rights related to that. For instance, in U.S. legal practice, lay witnesses can testify to facts, but only experts can offer opinions, inferences, or conclusions. It is also assumed that lay and expert inferences of the observed "facts" differ (Ryle 2009 [1949]). Legal, media and sport settings acknowledge an established status for experts, who are authorized and enjoy the privilege to give expert opinions and commentaries. In certain contexts, such as air traffic control, a set of specified skills, including expert vision, is taught for trainees to gain professional expertise (Koskela \& Arminen 2012). When professional expertise is acquired through a specified training, strict limits are set regarding who may be considered accredited professionals. In those contexts, expertise entails alleged trained and professional conduct and practices such as professional vision, vocabulary and reasoning.

However, the lay/expert division is also contestable, being prone to adversities and challenges (Lindwall \& Lynch this issue). On the one hand, for example, expert testimonies in court may be utilized for challenging the lay vision surrounding the course of the events (Goodwin 1994). On the other hand, lay people may challenge experts, either concerning their inferences and implications (van Burgsteden \& te Molder 2019) or the local relevance of their knowledge and expertise (Wynne $1992 ; 1996)$. On the whole, "science becomes controversial as soon as it touches on the question 'how 
to live"" (Versteeg 2018, 28). As soon as expert views overlap with everyday moral concerns, they become open for controversy. In some cases (e.g., in the diagnosis of ADHD), scientifically established views are interwoven into reality disjunctures between supporters and skeptics (Versteeg 2018). Sometimes experts are split into various camps, each of which claims to be supported by science, as is the case with responses to recreational drug use (Plant 1980). In a number of issues, when the proposed advice counters lay understanding and experiences, lay people may challenge expert views. In medical settings, the movement to humanize medical science has initiated concerns about the neglect of the patients' lifeworld in medical interactions (Mishler 1984). This concern has slowly led to increased interest in "experience expertise" in medicine, culminating in such hybrid notions as "lay experts" (Prior 2003). Within science and technology studies, Collins \& Evans (2007) have tried to solve the dilemma of lay expertise with their notion of "interactional expertise," which refers to deep linguistic socialization in the experts' specialist area, so that the criterion for interactional experts - who are not trained, contributory specialists in the field - is an ability to communicate fluently and reliably with contributory experts. Collins \& Evans (2007) aimed at setting standards for who is able to make a valid contribution to expert discussions. The evaluation of the validity of contributions to expert discussions has opened its own field of empirical analysis (Arminen et al. 2019).

In interaction, parties may draw on their lay or expert status while forming their actions. The expertise gradient is talked into being in various pedagogic settings in which the trainer builds her or his actions by relying on her/his expert status and treating trainees as less experienced. In our first example, the air traffic control (ATC) trainer poses a test question to a trainee concerning an approaching aircraft (OCC). Notably, both parties have equal access to the situation; they similarly see all the aircraft and ground vehicles on a 3-D simulator screen, and they have the same "know-that." Also, the trainee has been taught all the relevant knowledge concerning air traffic control work before the simulator exercises. The possible difference between the trainee and the trainer is in their know-how (i.e., expert status). In (1), the trainee (TE) guides and controls several aircraft in the air and a fire engine (F8) in the maneuvering area. The trainee has issued take-off clearance for a heavy military aircraft, which has just become airborne, freeing the runway for other traffic. At that point (lines 1-2), the fire engine (F8) poses a request to ATC, that is, to TE. But before TE has started to answer to the request, the trainer (TR) initiates a question concerning a pending task in overlap with F8's request (line 3).

\section{Example 1 (Koskela \& Arminen 2012)}

1

2

3
F8: palo kahdeksan jenkki bravossa saanko ajaa kiitotien fire eight at yankee bravo may I cross runway

[yksi kaksi yli?]

[one two.

TR: [>voisko charlie] [>could charlie] charlie continue approach.< 


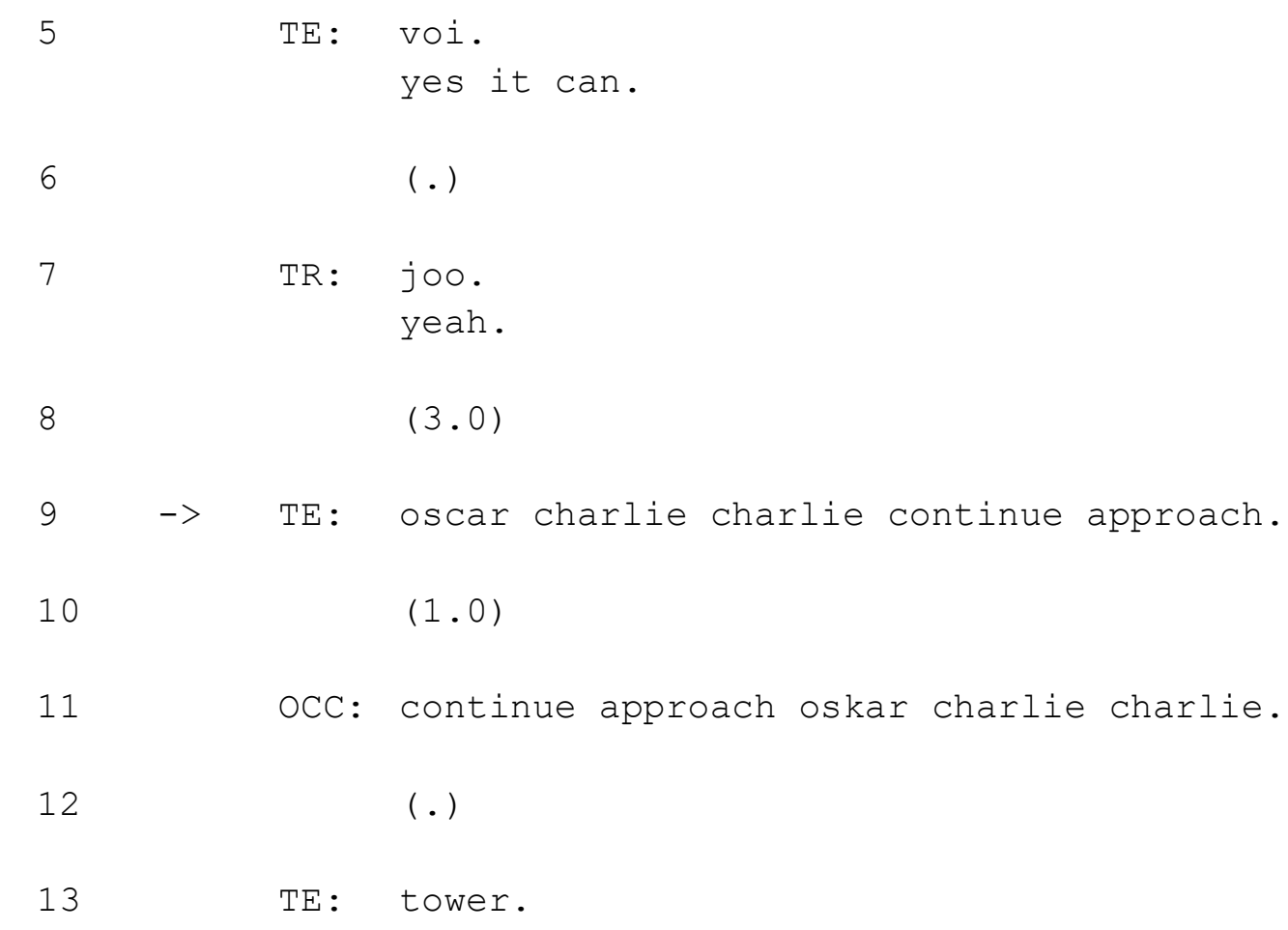

At line 3, TR interferes with the progress of the ATC work that TE is conducting. The positionoverlapping with the request - and the composition of TR's question at line 3-already there and then — show that TR knows what should be done next. The posing of a test question — namely, what to do next-shows that TR comprehends the ATC priorities and makes visible his expert status. Furthermore, as a reminder, the prompt calls attention to the pending task that TE has not carried out yet, thereby making visible the expert gradient between TE and TR. The timing of the question suggests ${ }^{\mathrm{ii}}$ that TR gives priority to the prompted task over the request for a runway crossing. That is, the air traffic has primacy over the ground traffic at the airport. The design of the prompt also occasions a preference for the clearance of the aircraft. To reach a professional, safe decision, TE has to ascertain what kind of aircraft is arriving and connect that to the prevailing traffic situation in the airspace and at the airport. To make a professional judgement, TE has to link the visible situation to its situated context and apply air traffic management rules to it. To achieve all this, TE attends to the flight information available (Figure 1; lines 3-5).

Figure 1. The trainee looks down on the strip of OCC

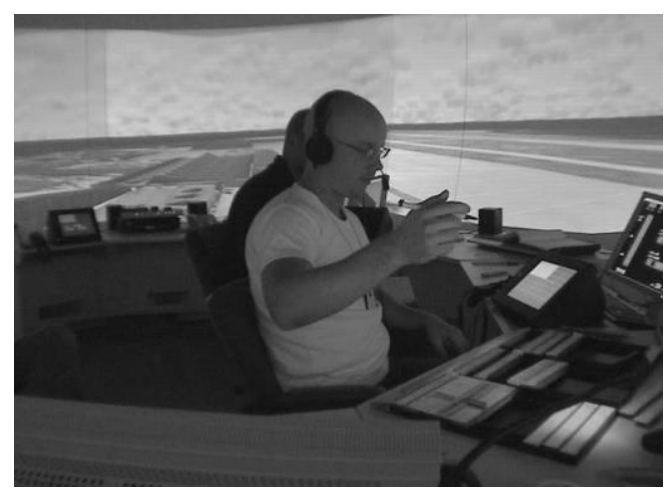

[FIGURE 1 AROUND HERE] 
It takes two seconds for TE to reach professional judgement about the situation, and then he gives an affirmative answer to TR (line 5). TR's confirmation (line 7) then crowns the shared understanding, and TE eventually executes the task (lines 9-13). The ATC training interaction is based on an expertise gradient between the parties, so that the relative level of expertise is the organizing structure of the interaction between them.

Professional practices may also constitute a professional realm, which is distinct from the everyday life of lay people. An expert community of practice may form an exclusive domain, the comprehension of which requires a professional expertise that lay people lack. Consequently, movement between the mundane world and the professional realm may require a translation. In the infamous Rodney King trial in 1993, an expert witness was called by the defense to testify and provide a professional vision of what had happened in a violent arrest that was videotaped. The police officers were put on trial and charged for excessive use of force, and the amateur photographer's videotape of the incident was used as evidence. In (2), following Goodwin (1994), we examine the courtroom interaction between the defense lawyer and the expert witness, Sergeant Duke. In his expert testimony, he applied a coding scheme to the entire incident so that the whole course of events in detail was transferred to a professional realm. The images visible on the tape, often in slow motion or stills, were coded, and relevant details highlighted and translated into expert vision and moved away from the mundane world. In (2), the defense, in co-operation, environmentally coupled with the simultaneously shown videotape, built up a translation, proposing a shift from a lay perspective to a professional vision regarding the violence.

\section{Example 2 (Goodwin 1994, 617; Arminen 2017)}

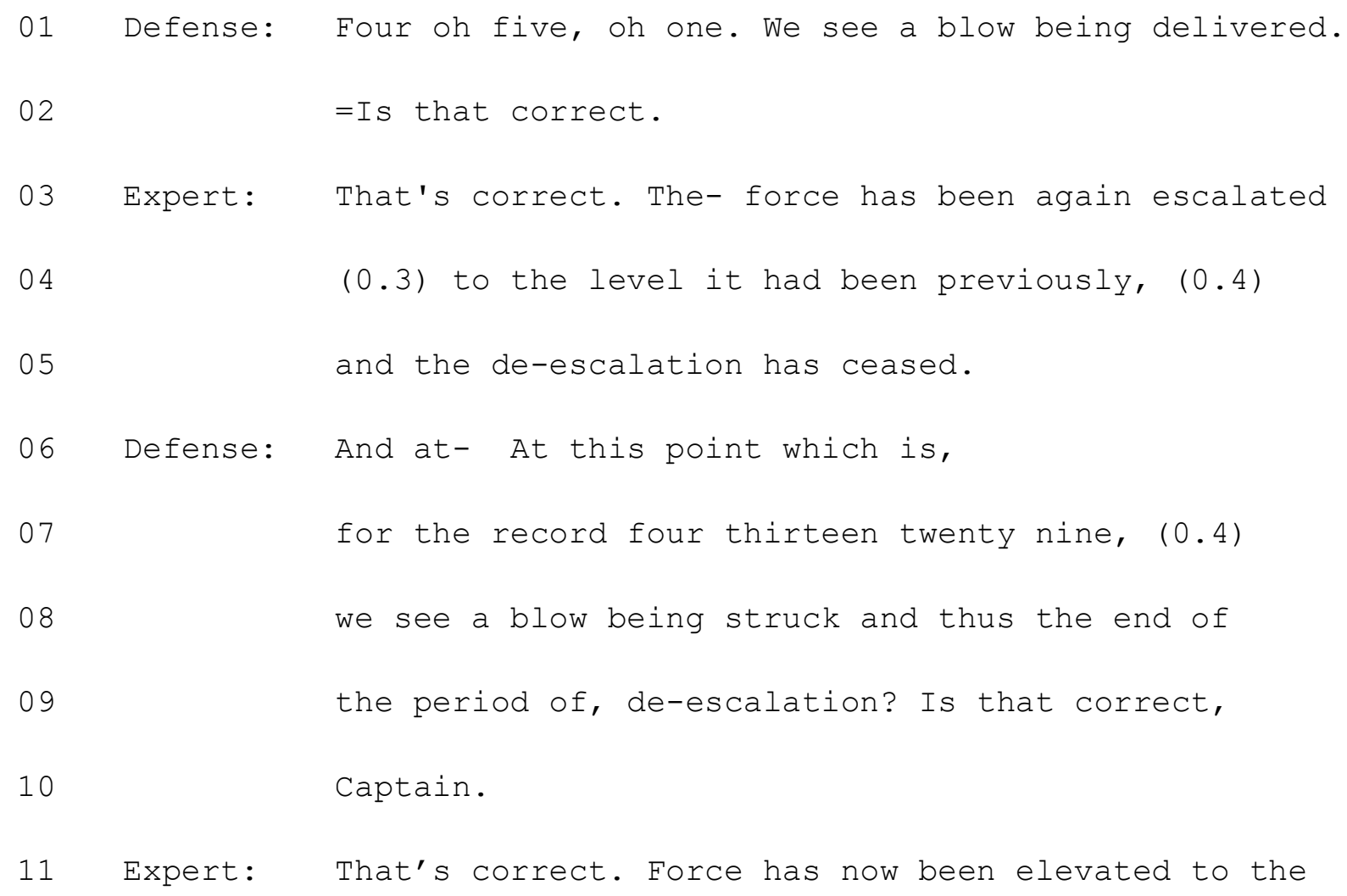


The defense lawyer refers to visible activities through lay terminology, thereby enabling the untrained recipients' understanding with their default language. Thereafter the expert provides a translation into a technical vocabulary (e.g., rephrasing "a blow" by "cease of de-escalation." The defense thus cooperates to offer a translation from a lay perception to an expert vision, which is completed at line 9 and confirmed at lines 11-13. This teamwork further establishes the supremacy of the expert vision by presenting it as an outcome of a translation. Furthermore, the translation not only requires a rescripting of the sequence of action; it also leans on recoding the understanding of the event, thereby providing an alternate sense of the course of events, which shakes our predominant lay understanding that perception as such would provide accurate knowledge. The recoding is also prone to altering the moral sense of the event: the ordinary language account describes it in agentive terms (e.g., who hits whom), whereas the professional account hides the moral agency and traverses it to subjectless elevations and de-escalations of forces. Potentially varying moral orders between the professional and lay worlds may also open conflicts, if ordinary people do not accept the moral order encoded in the professional realm. Notably, after the acquittal of police officers in the Rodney King trial, a massive uprising took place, rocking Los Angeles and leading to destruction in large areas of the city, and a lengthy legal aftermath was opened.

Together, our findings suggest that expertise matters to participants: how they conduct their behavior, what they see, how they act, and how they relate to each other. It appears that expertise in interaction may entail observable invariances. We have to draw the conclusion that expertise in interaction is a potential research object for EM/CA.

\section{Understanding and seeing the implications of the fact}

Knowing-how and knowing-that have a different relationship with the practice. Know-how always has a potential to be actualized in performance, and a person with know-how is potentially a practitioner in a community (Goodwin 1994; Hindmarsh 2010). The tie to the communities of practice binds expertise to the questions of communal morals and authority. Within epistemics, people are divided between those who know and those who don't; within expertise, people are split between the competent members of a community and outsiders. In that way, expertise poses a division between those who are able to participate and those who are not, and learners participating peripherally (Lave \& Wenger 1991). Intrinsic ties to a practice may mold the way in which expertise and its distribution form the basis for interactants to adjust and reshape their actions, participate and understand their participation. The expertise may enable a party not only to see "the facts" but also to draw inferences from them, which invokes issues of authority more than in epistemics. Knowledgeability is displayed through a grasp of facts, whereas expertise yields to the implication of facts. The ties of expertise to a grasp of the implications of facts comprise an internal connection to the realm of morals (Versteeg \& te Molder 2018). 
Expertise is a distinct domain that differs from epistemics, also in its duration of distribution; much of the know-that can be transferred to those of not-knowing by direct communication, whereas knowhow as a dispositional excellence requires training and rehearsing, making its achievement timeconsuming. This comes out also in differences between the types of knowledge: ubiquitous knowledge is transient — we see whether it is raining just by looking outside — while technical or scientific knowledge - that is, expert knowledge - requires years of study. Ryle (1945) initially suggested that eventually all knowing-that is based on knowing-how, not the other way round, as commonly thought. In any case, the acquisition of expert knowledge and expertise requires extensive, time-consuming specialized training. But as there is ubiquitous knowledge, there can also be ubiquitous expertise (Collins \& Evans 2007). Also for Ryle (2009 [1949], 17) know-how is most mundane matter, consisting of issues, such as "how to make and appreciate jokes, to talk grammatically, to play chess, to fish, or to argue". A wide variability of know-how leads to varying forms of conventionalized know-how, and borderline cases of expertise. We could think of parenting as a candidate for a good example of "ubiquitous expertise." Parenting skills are not automatic, and they are not habits that could be drilled (Ryle 2009 [1949], 30), nor are there formal long-term training facilities to train in them. Furthermore, there are no formal criteria for successful parenting; anyhow, we tend to have strict views of good and bad parenting, and a vivid capability to distinguish those. To spell out the consequences, it is not certain that we can tell "good parenting" —or, to paraphrase Ryle, when parenting is done "well, i.e. correctly or efficiently or successfully" — but definitely we can see its lack.

One of the central differences between propositional knowledge and expertise is that the latter implies not just seeing the facts but also comprehending their meaning. The ability to take into account implications of the facts and infer what to do ties expertise to practices and moral reasoning. In as much as expertise can be regarded as a capacity to evaluate the consequences and morals of the issues, it has some higher value, but also a heightened controversiality. In this section, we investigate two cases of how parties in interaction may provide different understandings and implications of a fact, depending on their level of expertise. First, at the home of a newborn baby, a health visitor (HV) comments on some sucking behavior of the baby. The baby's father (F) and mother $(\mathrm{M})$ respond to the comment almost simultaneously but in different ways, which we might call displaying "knowing a fact" and the other "understanding the implications of a fact."

\section{Example 3 (Heritage \& Sefi 1992: 367; Arminen 2017)}

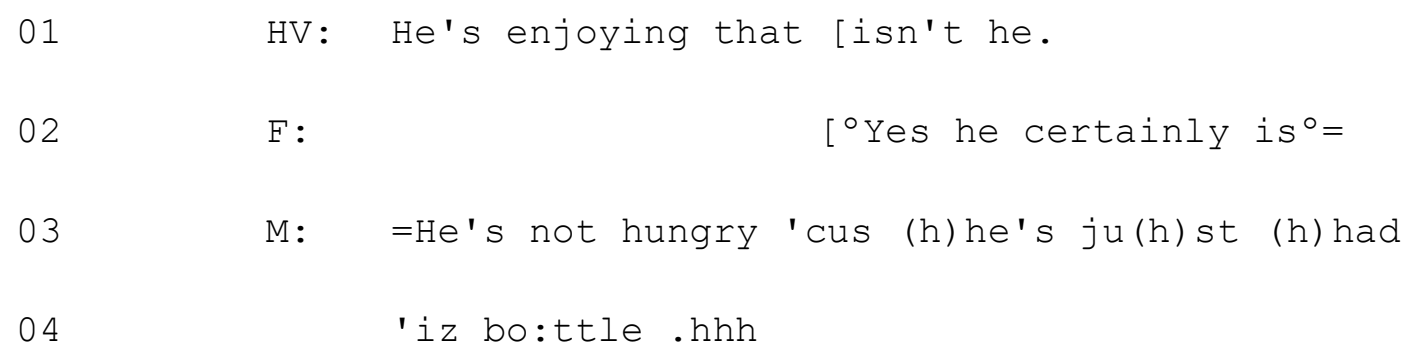

The father aligns with the health visitor straightforwardly, displaying pure agreement. Conversely, the mother's reply is defensive; she rebuts the health visitor's implications (see also Heritage \& Sefi 1992; Arminen 2017). For the mother, the remark “he's enjoying that, isn't he" implies blame. The 
mother's response shows that - according to her-the health visitor did not express innocent delight but concern about the baby's welfare. The health visitor's remark invoked the mother's self-conscious caretaker role; she presents herself as the moral agent, who is responsible for the child's welfare. Thus, the mother defends herself from the health visitor's critique, as she heard it.

The defensive response to the health visitor (whom the father understood innocuously) makes public the mother's understanding of the situation. She sees the health visitor as an authority who is there to judge and control her. Accordingly, the mother also displays her orientation to the institutionality of the event or builds a situated sense of the institution, making it procedurally relevant. No less, the family as an institution, with its own division of labor, is also made relevant here, so that how the parents express their roles toward the health visitor reveals their job division (ibid.). The mother constructs herself as the principal moral agent of the family and the health visitor's client under evaluation, whereas the father constructs himself as a mundane co-conversationalist with the health visitor. In that way, the mother attends to the institutional implications of a fact, whereas the father attends to "seeing a fact"; thereby they embody different degrees of expertise, according to their division of labor, with one party being more deeply morally implicated in the event that both parties equally see.

Also in the next extract, there is a striking disparity in how the parties formulate their responses. The case comes from a peer group interaction in 12-step addiction treatment (i.e., a group of patients having a session together, without the therapist of the clinic). They had been asked to discuss how they were doing six months after the treatment. The extract starts with an answer given by Tiina (T), one of the patients, and it is followed by a senior member's (M2) suggestion. The senior member acts as a secretary of the group, and proposes what should be written down for the therapist to read.

\section{Example 4 (VR 2 20:3-10; Arminen 2009)}

T: $\quad$ EMää vastaan et emmä tie ${ }^{\circ} \mathrm{d}(\mathrm{h}) \ddot{a}^{\circ}$, hhhe hy hy (.) . vhhh fI'll answer that I don't $\mathrm{kno}^{\circ}(\mathrm{h}) \mathrm{w}^{\circ}$, hhhe he he (.). vhhh

T: Ehkä raittiina?, (0.6) Ehkä en $e^{\circ}$ lossakaa . hh Perhaps sober?, (0.6) Maybe not even $a^{\circ}$ live ${ }^{\circ}$. hh 
Hop [efully sober I guess (.) one c'd say?, h

The discrepancy between Tiina's answer (lines 1-3) and the senior member's candidate answer (line 6) highlights a contrast between an individual viewpoint and an answer suitable for the therapist. Tiina's answer offers her rather grim lay understanding of her situation as a middle-aged addict. The senior member (M2) orients to his role as a secretary and utilizes his experience expertise to suggest what he thinks the therapist would like them to report to her. The senior member's account provides a clear-cut contrast to a less-experienced member's account. With his expertise, the senior member orients to the prescribed treatment ideology of the clinic, which aims at building agency among its patients. In that way, the senior member engages with moral work, giving an ideal answer and imputing agency to an addict who after treatment is still working at recovery, that is, an answer in which an actor in charge exists (see Pomerantz 1984). This moral work also entwines with hope work, and the experience-based expertise is entangled with the morally embedded therapeutic practice, handing authority over to the senior member to tell another member how to envision her future.

Through the tie with practices, expertise gains a moral dimension, which links it also to questions of authority. As far as expertise concerns implications of facts, it connects with questions about what should be done. The question about what should be done now is tied to responsibilities and agencies, as well as goals (see Stevanovic, this issue).

\section{How to study expertise in interaction}

Heritage (2013, 371-372) points out that on the well-known TV program Antiques Road Show, there takes place publicly a nice claim of expertise when the owners of the object in question are asked whether they "have any idea what this is worth." The negative polarity item "any" invites a deep gradient between the lay owners and the experts doing the appraisal of the object. In the show, the expertise is then demonstrated publicly, as the appraisal is done environmentally coupled with the object, and the owner of the object follows the emergent appraisal on the spot. In some contexts, such as when interaction is directed to an overhearing audience, both in media (Fele \& Campagnolo, this issue) and also in courtrooms (excerpt 2), there are both public claims and demonstrations of expertise. Similarly, it is well demonstrated in trainer-trainee situations, where the trainer may make observable something that the trainee should see or do (1), or when the expert and lay views are contrasted $(3 \& 4)$. These are all cases where the gradient of know-how between participants is sharp and clearly demonstrated.

In those contexts where there is no training or overhearing audience or work is carried out among professionals, the ways in which expertise is exuded are often subtle or subliminal, and they may remain seen but unnoticed. Among peers working in routine tasks, the dispositional excellence is not separately displayed but just an inherent aspect of the execution of the activity, nor is its reception 
marked (Bassetti, this issue; Harms, Koole, Stukker \& Tulleken, this issue). In these cases, the excellence or know-how is inbuilt in the performance and its efficiency, and they pose a challenge for the analyst. An easy solution is to classify professionals' or educated practitioners' actions as expert activities. As convenient as this solution may be, it bears a risk of missing a display of dispositional excellence, and just bluntly ascribes expertise as synonymous with the professional title, accreditation or educational background of the participants. Already Garfinkel reminded that these kinds of ascriptions of social practices are inadequate, as they fail to reveal how social actions are achieved (Hak 1995; Arminen et al., forthcoming). If we give up on the bucket theory of context above, we become sensitized to the local assemblance of action. Nevertheless, the sensitive reading of excellence in action may require a special skill from the analyst. When an agent orients to expert knowledge or expertise that is taken for granted in the practice in question but not known to outsiders, the recognizability of the activity may depend on the analyst's access and ability to see the locally relevant distinctions (Arminen 2000). In other words, the analysis of expert action is dependent on sufficient knowledge to be able to recognize what the activities mean for the parties themselves. ${ }^{\text {iii }}$

The excellence of performance is bound to rule-based practices enabling standards that allow assessments. The constraint on specified rule-bound practices may seem to narrow the domain of expertise to institutional interactions in which agents have tasks and goals defined by institutions. Know-how as presented by Ryle is a much broader category, however, and all instances where expertise touches upon everyday life and its concerns are bound to form hybrid domains, such as lay experience and expertise. If we rule out hybrid domains of expertise and narrow it down to its accredited forms, we may fail to reveal how parties in interaction consider expertise. We should be receptive to exploring parties' artful practices for exposing excellence in interaction. In that way, we may be open to analyzing forms of ubiquitous expertise in practices, such as parenting, and expertise not bound to institutional domains but to specifiable practices, the performance of which can be assessed in terms of success or efficiency_or, minimally, their failure.

Through the next examples, we reflect on how to study expertise. We point out the salience of rulebased practice and professional knowledge and the analyst's access to them as a prerequisite for analysis. As a case in point, survey research interviews are an example of the interviewer's use of ubiquitous interactional knowledge applied to a specific institutional practice to balance between the social requirements of the situation and the standardization of the interview. The following case (5) is from a baseline interview for a governmental project promoting job seekers' employment capacities. In line 1, the interviewer (IR) is reading aloud standardized questions from a questionnaire concerning functional capacities (i.e., the interviewee's (IE) capability to cope with various ordinary situations). We will focus on lines 3-7, which are revealing in terms of IR's expertise.

\section{Example 5 (Simonen 2017)}

01 IR: pystyttekö liikkumaan >metsässä.< (0.2)

are you able to walk >in the woods.< (0.2)

02

esimer(k)iks kerään (0.2) marjoja ja sieniä.=

for example to gather (0.2) berries and mushrooms.= 


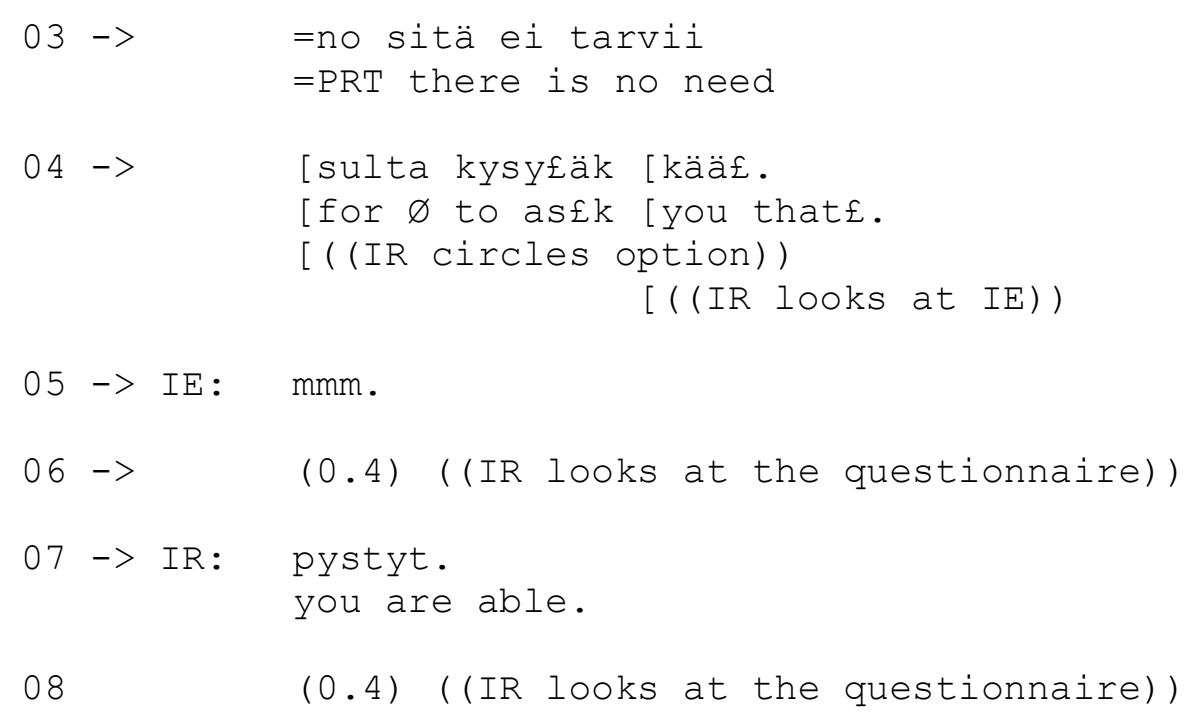

After reading the question (lines 1-2), IR (line 3) marks the departure from the standard format with a turn-initial particle [no] (Vepsäläinen 2019). IR — after just reading the question — states that there is no need to ask this question from IE. In that way, IR builds and marks a special relationship with IE. In line 3, instead of initiating to go through the standard 5-set answer options-Yes, without difficulty; Yes, but with difficulty; No, I'm not able to; I don't know, I cannot-IR displays her knowledgeability of IE with a smile in her voice, ascribing to herself the capability to answer on behalf of IE. By withholding the answer options, IR displayed both an evolved understanding between the parties and a positive recognition of IE's capabilities, potentially motivating IE's continuation in the interview. Moreover, IR avoids face-threatening answer options and saves time with the preemption, thereby maintaining efficient progress of the interview.

However, when IR's compliment uttered with a smile and a brief gaze to IE got only a minimal response (line 5), IR returns to the official frame of the interview by stating aloud the answer "you are able" (line 7). Through the return to the answer options, IR also marks the return from an unofficial side move to the official frame of the interview. In that way, the interviewer subtly displays - through the movements to and from the interview frame-her capability to both orient to the social aspects of the situation and maintain the objective neutrality of the standardized interview. Of course, the interviewer's ability to shift frames depends on her degree of freedom from a tight objectivistic measurement; here the shift to a positive recognition of the interviewee's capabilities fits well with the overall frame of the governmental project promoting job seekers' employment capacities. From a methodological point of view, the reading of the agent's expertise depended on the analyst's knowledge of the practice, so that the analyst could see and appreciate the particular way in which IR carried out her rule-based institutional task, which still allowed a personal fingerprint in the achievement of the task.

The next case (6) is from an interview for a project supporting elderly people's independent living at home. The interviewer (IR) is a nurse working for a day-care center for elderly people that the interviewee (IE) attends. Due to IR's and IE's relationship, IR has basic knowledge of IE's family relationships, including her grandchildren. IE suffers from memory loss, the severity of which varies. In the interview for the project, IR collects information on IE's family relationships. We will focus 
on how IR deals with an answer (line 8) that appears to be problematic for her (lines 13-15). This allows us to focus on IR's expertise in dealing with contingencies arising from interviewing people with memory loss. When we arrive at the scene, both speakers are looking at the questionnaire sheet on the table. IR is reading a question aloud (line 1).

\section{Example 6}

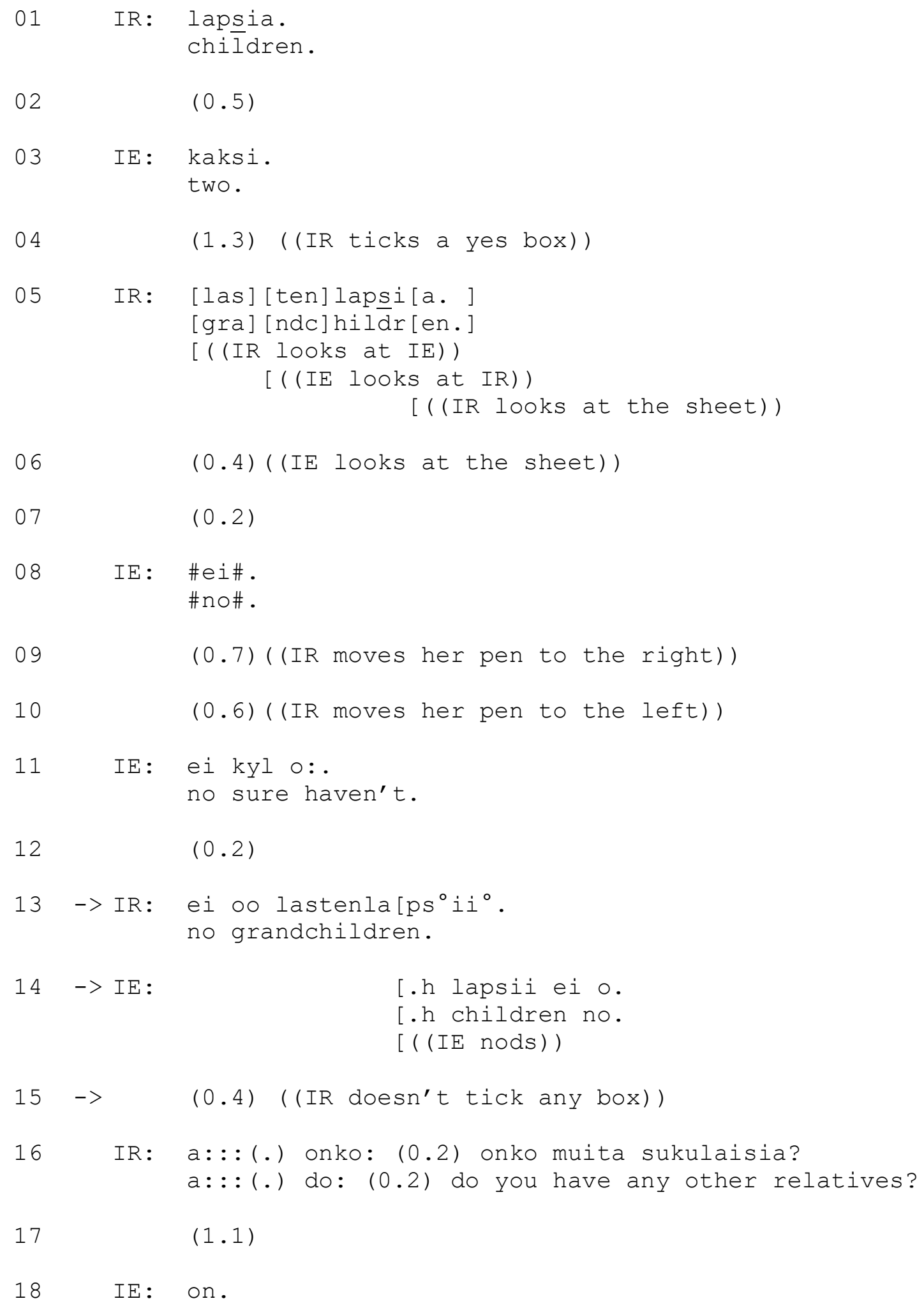


yes there are.

In the interview on family relationships, IR presents questions of family members in a truncated way without question verbs (lines 1 and 5) and records the answer routinely in line 4 . While uttering the question in line 5, she marks it by shifting her gaze at IE, who responds with hers. At the end of her question, IR then drops her gaze, evading IE's look. IE's gaze then follows IR's gaze downward (line $6)$.

After IE's delayed negative answer (line 8), IR allows a long pause and refrains from writing the answer down (lines 9-10) but does not reject it (c.f. Simonen 2012). After the prolonged pause, IE strengthens her negative answer with a clausal version (line 11), marking orientation to a disagreement: "no sure haven't" (Keevallik \& Hakulinen 2018). In that way, IE treats IR's pause as a delay, which for her represents a sign of dispreference. Notably IR did not explicitly confront IE, but gave her time to allow her to revise her answer. The opened silence provokes IE to challenge a disagreement. After a 0.2-second pause following IE's second answer, IR takes finally a turn (line 13) and confirms the answer given twice to her. IE then confirms IR's candidate understanding, and provides the answer once again (line 14).

Notably, still after the answer has been confirmed three times, IR chooses not to write it down (line 15). ${ }^{\text {iv }}$ Instead, IR moves to the next question (line 16). The question is produced with restarts, and its design is more complete than the previous questions, including the question verb: IR seems to offer a chance to restart the interview again.

In (6), the interviewer displays her expertise in dealing with older adults with a mental impairment, such as a memory loss. She is careful not to confront or agitate the person in a vulnerable stage. ${ }^{\mathrm{v}} \mathrm{By}$ giving time to the recipient, she orients to her task of providing standardized information. In all this, the interviewing nurse shows her expertise by managing to treat the older adult as if she would be the primary source of knowledge about her social relations (e.g., grandchildren) (Raymond \& Heritage 2006).

The next case (7) demonstrates how the analyst's reading of interactional practice is embedded in his/her knowledge of the practice, and how that knowledge becomes relevant in the course of analysis. It is from an Alcoholics Anonymous (AA) meeting; the speaker M (Marja) is telling about when she lived with a partner who did not drink but had an alcohol problem. The analysis focuses on the selfrepair at line $3^{\text {vi }}$.

Example 7 (Arminen 2000；2017)

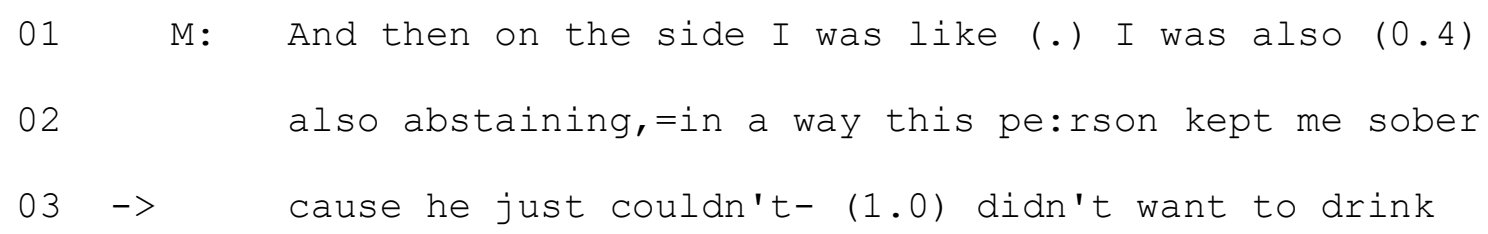


himself, and didn't either approve of me drinkin. (.)

In line 3, Marja makes a self-repair, which ascribes two ways to see abstinence: inability to drink and unwillingness to drink. With the repair, the speaker replaces the former with the latter. The accounts give a different moral character to the abstinence: inability stands for actions the agent cannot control, whereas willingness stands for deliberate actions. Therefore, the repair makes relevant a distinction between an exterior compulsion and a voluntary choice. In that way, repair may carry moral and ethical implications. Here the speaker seems to be committed to moral work through which an actor in charge is constructed. To characterize further abstinence as a moral object, the analyst would benefit from knowledge of the expertise of the speaker. It appears that the distinction the speaker has uttered is not just any random difference but a formulation of a central idea of Alcoholics Anonymous. According to AA, "the only requirement of AA membership is a desire to stop drinking" (Anonymous 1952). With the help of this knowledge, the analyst can see that that, without so many words, the speaker ascribed an AA identity to her partner. One might add that the repair was not idiosyncratic, but the speaker made an effort to spell out a correct identity for the person in question. Had she not made the correction, she would have cast a false identity on the person and committed herself to morally negligible behavior. In any case, the salience of the repair was connected to AA beliefs. While it is obvious for those with know-how to see the connection to AA's program, for those who do not have the sufficient background knowledge the point might have been missed. The case has methodological relevance; it shows the way in which the analyst's expertise is reflexively embedded in the explication of data. The understanding of the meaning of the action requires certain expertise from the overhearing analyst as well; otherwise, the analysis may risk losing the actor's special expertise, which informs of the achievement of the action.

\section{Discussion}

In this article, we set out a task to address expertise as a distinct form of knowledge, and tried to determine and detail its specificity and consequentiality in interaction. We found several ways how expertise appeared in our analyzed cases. First, a trainer's use of test questions to incite and develop trainees' professional vision and practice makes observable the expert status and a deep expertise gradient between parties (excerpt 1). The gulf between lay and expert realms was demonstrated further, when a translation from a lay terminology to the expert witness' professional vision was offered in court (2). The participants' adjustments of their actions and understandings according to their "know-how" and consequent assumptions about others' knowledge-based views provide further evidence for the relevance of distribution of expertise in interaction. Thus, expertise allows a party to see the implications of a fact, whereas the lay party was limited in seeing the fact, lacking access to the implications other competent participants saw (3). The implications of a fact can also touch on a moral dimension and connect expertise with authority (4). When in an interview the interviewer tailored her performance according to the institutional requirements of standardization and the maintenance of a situational, intersubjective understanding, an institutionally embedded use of ubiquitous expertise surfaced (5). Expertise may also come out in withdrawals from performing 
ordinary canonical actions to achieve professionally sensitive practice with clients (6). Finally, inspection of expertise in interaction is reflexively embedded in the analyst's context-sensitive understanding of the practice studied; in particular, this can occur in analyzing interactions among peers possessing distinct knowledge and know-how that is taken for granted in the practice in question (7).

\section{Conclusions}

The notion of knowledge used in CA might benefit from re-specification, as there may appear to exist several types of knowledge that are relevant for parties in interaction in different ways. In particular, "knowing-that" and "knowing-how" have distinct relevancies for participants in interaction. Displays of knowing the facts of the world establish the former; showing knowing how to do things marks the latter. We propose that the latter is expertise in interaction. Similarly, as participants in certain cases can be seen to adjust their actions and understandings according to their sense of what they know and assume others to know, the participants" "know-how" and its distribution may form the basis for adjusting and reshaping their actions, forms of participation and understandings. Expertise may also amount to a vision concerning the implications of the fact that may grant experts authority to evaluate what to do next, but in that experts may run into an "is/ought" dilemma, or so-called Hume's guillotine: "the distinction of vice and virtue is not founded merely on the relations of objects, nor is perceived by reason" (Hume 1739, 470). To say the least, this marks what different consequences expertise may have in contrast to knowing-that, revealing that expertise may become involved in moral debates. Expertise as a form of knowledge may also be in a tension with some presuppositions of epistemics, in which it is commonly held that firsthand knowledge supersedes secondary knowledge (e.g., Heritage 2013). In some cases, professional vision may cast doubt on the accuracy of lay perceptions (Lindwall \& Lynch, this issue). It may be that the epistemic status of a perception could be reconsidered; in his critique of the myth of the given, Sellars (1956) criticized the view that there existed a perceptual knowledge independently of the conceptual processes in perception. Similarly, expert vision may challenge lay perceptions that just seem to have supposed what has happened but have not comprehended what has happened.

Another methodological issue concerns the limits of expertise. It may seem natural to propose that expertise is limited to professional contexts in which parties may have specialized knowledge used in practices aimed at institutional goals. Following not only Gilbert Ryle but also methodological canons of EM/CA, we might consider expertise as an excellence in the performance of practices where parties may have learned or been trained to perform an accomplishing action. This view of know-how or expertise would extend to hybrid areas of ubiquitous expertise, such as parenting. Notably, expertise seen in this way would be a broader category than professional practice, but still limited. We propose that expertise covers all practices that can be assessed and evaluated, so that performance can be ranked in terms of its correctness, efficiency or subtlety. Though this definition covered a broader area than institutional interaction, it were limited to evaluable activities, and Bassetti (this issue) has shown evaluations can be explicit or implicit. But there are also activities that are not evaluable. Greetings are recognizable bounded activity, for example, but they are not evaluated in everyday life. We can see a greeting, or its lack, and we can see how it is done, whether 
it is minimal or grand, verbal or nonverbal, but we do not have a scale to evaluate it. There have to be rule-based practices enabling standards that allow making an action evaluable, so in Stalin's court, at Starbucks and in the Commonwealth queen's entourage greetings can be assessed up to a detail. Indeed, we have a lot of evaluable activities, which we routinely assess, and we should be able to grant evaluable activities the merit they deserve and explore how excellence and expertise in interactions are ranked or rewarded in practice.

\section{References}

Anonymous. (1952). Twelve Steps and Twelve Traditions. New York.

Arminen, I. (2000). On the context sensitivity of institutional interaction. Discourse \& Society, 11(4), 435-458.

Arminen, I. (2009). On comparative methodology in studies of social interaction. In: Haakana, M., Laakso, M. \& Lindström, J. (eds.) Talk in interaction: comparative dimensions. Helsinki: Finnish Literature Society, 48-69.

Arminen, I. (2017). Institutional Interaction. Studies of Talk at Work. Routledge.

Arminen, I., Kallio, A., \& Mälkia, T. (Frthc). Beyond deontics - influencing decision making process in the management meetings. In: Porche et. al. (eds.) Institutional Matters. Postdisciplinary Analysis of Political Concerns. Palgrave.

Arminen, I., Segersven, O. E., \& Simonen, M. (2019). Active and latent social groups and their interactional expertise. Acta Sociologica, 62(4), 391-405.

Bassetti, C. this issue.

Brown, D. G. (1970). Knowing how and knowing that, what. In: Wood O.P., Pitcher G. (eds) Ryle. Modern Studies in Philosophy. Palgrave, 213-248.

Collins, H. \& Evans, R. (2007). Rethinking expertise. Chicago: The University of Chicago Press. Drew, P. (2018). Epistemics in social interaction. Discourse Studies, 20(1), 163-187.

Fantl, J. (2008). Knowing-How and knowing-that. Philosophy Compass, 3(3), 451-470.

Fele, G. \& Campagnolo, G. this issue.

Goodwin, C. (1994). Professional Vision. American Anthropologist 96(3), 606-633.

Hak, T. (1995). Ethnomethodology and the institutional context. Human Studies, 18(2-3), 109137.

Harms, Koole, Stukker \& Tulleken this issue.

Hayano, K. (2013). Question design in conversation. In: Sidnell, J. \& Stivers, T. (eds.) The Handbook of Conversation Analysis. Chichester: Wiley-Blackwell, pp.395-414.

Heath, C. (2012). The dynamics of auction: Social interaction and the sale of fine art and antiques. Cambridge: Cambridge University Press.

Heritage, J. (2012). Epistemics in action: Action formation and territories of knowledge. Research on Language and Social Interaction 45(1): 1-29.

Heritage, J. (2013). Action formation and its epistemic (and other) backgrounds. Discourse Studies 15(5): 551-578.

Heritage, J. \& Sefi, S. (1992)." Dilemmas of advice: Aspects of the delivery and reception of advice in interactions between health visitors and first-time mothers." In: Drew, P. \& Heritage, J. (eds) Talk at Work. Interaction in Institutional Settings. Cambridge: Cambridge University Press, pp.359-419. 
Hindmarsh, J. (2010). Peripherality, participation and communities of practice: Examining the patient in dental training. In: N. Llewellyn \& Hindmarsh, J. (eds.) Organisation, interaction and practice. Cambridge: Cambridge University Press, pp.218-240.

Hume, D. (1739). Treatise of Human Nature.

https://en.wikisource.org/wiki/Treatise of Human Nature/Book 3: Of morals/Part 1/Section 1 (Retrived 25.9.2020)

Keevallik, L., \& Hakulinen, A. (2018). Epistemically reinforced kyl(lä)/küll-responses in Estonian and Finnish: Word order and social action. Journal of Pragmatics, 123, 121-138.

Koskela, I. \& Arminen, I. (2012). The embedded evaluations in air traffic control training. In: Rasmussen, G. Brouwer, C. E. \& Day, D. (eds.) Evaluating Cognition in Interaction. Amsterdam: John Benjamins, pp.15-42.

Lave, J., \& Wenger, E. (1991). Situated learning: Legitimate peripheral participation. Cambridge university press.

Lindwall, O., Lymer, G., \& Ivarsson, J. (2016). Epistemic status and the recognizability of social actions. Discourse Studies 18(5), 500-525.

Lindwall, O. \& Lynch, M. this issue.

Lynch, M. (2006). The origins of ethnomethodology. In: Gabbay, D., Thagard, P. \& Woods, J. (Series eds.) \& Turner, S. \& Risjord, M. (Vol. eds.) Philosophy of anthropology and sociology. Vol. 15. Handbook of the philosophy of science. Amsterdam: North-Holland, Elsevier, pp.291-319.

Lynch, M. \& Macbeth, D. (2016). The epistemics of Epistemics: An introduction. Discourse Studies 18(5): 493-499.

Maynard, D. W. (2003). Bad news, good news: Conversational order in everyday talk and clinical settings. Chicago: University of Chicago Press.

Maynard, D. W., Houtkoop-Steenstra, H., Schaeffer, N. C., \& Van der Zouwen, J. (2002, eds.). Standardization and tacit knowledge. Interaction and Practice in the Survey Interview. New York: Wiley.

Mishler, E. G. (1984). The discourse of medicine: Dialectics of medical interviews. Norwood, New Jersey: Ablex Publishing.

Mondada, L. (2003). Working with video: how surgeons produce video records of their actions. Visual Studies 18(1), 58-73.

Nguyen, H. t. (2012). Developing Interactional Competence. A Conversation-Analytic Study of Patient Consultations in Pharmacy. Houndmills, Basingstoke, Hampshire: Palgrave Macmillan.

Plant, M. A. (1980). Drugtaking and Prevention: The Implications of Research for Social Policy. British Journal of Addiction, 75 (3): 245-254.

Pomerantz, A. M. (1984). Giving a source or basis: The practice in conversation of telling 'how I know'. Journal of Pragmatics, 8(5-6), 607-625.

Prior, L. (2003). Belief, knowledge and expertise: the emergence of the lay expert in medical sociology. Sociology of health \& illness, 25(3), 41-57.

Raymond, G. \& Heritage, J. (2006). The epistemics of social relationships: Owning grandchildren. Language in Society 35(5): 677-705.

Ryle, G. (1945). Knowing how and knowing that: The presidential address. In Proceedings of 
the Aristotelian society (Vol. 46, pp. 1-16).

Ryle, G. (2009/1949). The Concept of Mind. 60th Anniversary Edition. Milton Park, Abingdon, Oxon: Routledge.

Sellars, W. (1956). Empiricism and the Philosophy of Mind. Minnesota studies in the philosophy of science, 1(19), 253-329.

Sidnell, J. \& Stivers, T. (2013, eds.) The Handbook of Conversation Analysis. Chichester: WileyBlackwell.

Simonen, M. (2012). Mutual negotiation of the interviewee's competence in interview interaction. In: Rasmussen, G., Brouwer, C. E. \& Day, D. (eds.) Evaluating 'Cognitive' Competences in Interaction. Amsterdam: John Benjamins, 119-143.

Simonen, M. (2017). A Conversation Analysis of Social Interaction in the Functional Capacity Interview. PhD Dissertation, University of Helsinki.

Stevanovic, M. this issue.

Stivers, T., Mondada, L. \& Steensig, J. (2011, eds.). The Morality of Knowledge in Conversation. Cambridge: Cambridge University Press.

Ten Have, P., \& Psathas, G. (1995). Situated order: Studies in the social organization of talk and embodied action. Washington, DC: University Press of America.

van Burgsteden, L. M. \& te Molder, H. (2019). "The foot in the door": undercutting expertise and controlling the interactional agenda. Presentation held at IIEMCA 2019, Mannheim.

Vepsäläinen, H. (2019). Suomen no-partikkeli ja kysymyksiin vastaaminen keskustelussa. [The Finnish no-particle and answering to questions in conversation] PhD Dissertation, University of Helsinki.

Versteeg, W. B. (2018). "How do you know?”: Everyday negotiations of expert authority. PhD Dissertation, University of Twente.

Versteeg, W. \& te Molder, H. (2018). 'You must know what you mean when you say that': the morality of knowledge claims about ADHD in radio phone- ins. Sociology of health \& illness, 40(4), 718-734.

Whalen, J. \& Vinkhuyzen, E. (2000). Expert systems in (inter)action: diagnosing document machine problems over the telephone. In Luff, P., Hindmarsh, J. \& Heath, C. (eds.)

Workplace Studies: Recovering Work Practice and Informing Systems Design. Cambridge:

Cambridge University Press, pp.92-140

Wynne, B. (1992). Misunderstood misunderstanding: social identities and public uptake of science. Public understanding of science, 1(3), 281-304.

Wynne, B. (1996). A reflexive view of the expert-lay knowledge divide. In: Lash, S. et al. (eds.) Risk, environment and modernity: Toward a new ecology, pp. 44-82.

\footnotetext{
${ }^{\mathrm{i}}$ Hanh thi Nguyen works mainly in the field of interactional competencies, which is broader area than expertise, e.g. linguistic competence vs. expertise in linguistics. However, in her study of Patient Consultations in Pharmacy she addresses also issues related to expertise in interaction.

ii The pedagogy in ATC tends to be auspicious, i.e., the trainers do not give misleading prompts, but their prompts tend to signpost a "good practice."

iii The extreme requirement for the analyst competence would be unique adequacy requirement, according to which the analyst should have the competence of the practitioner studied. (see e.g., Lynch 2006).

iv This can be documented from a scanned questionnaire (which is not shown here).
} 
${ }^{\mathrm{v}}$ We have data from the later moment of the encounter when another nurse tries to help/confront the person to remember, which leads the person into a severely agitated state.

${ }^{\mathrm{vi}}$ Essentially the analysis concerns the disambiguation of the referent, and we show that to understand the referent the way parties in interaction do, you have to share the sufficient amount of their knowledge of the program, i.e., their expertise. Analysis entails a formal explication of the expertise. 